\title{
The research on vegetation configuration of urban wetland park revetment
}

\author{
Wendi $\operatorname{Tan}^{1, a}$ \\ ${ }^{1}$ North China university of science and technology, Tangshan, Hebei, 063009, China \\ a417041437@qq.com
}

\begin{abstract}
Keywords: urban wetland park; revetment; ecological; artistry; hydrophilic
Abstract. Revetment is a amphibious zone with ecological sensitive, has obvious marginal effect, affected by the hydrophilic psychology, revetment becomes tour destination for tourists, Human activity impacts on the revetment vegetation. This paper makes research on the vegetation configuration of urban wetland park revetment, proposes three basic principles, the first is the ecological principle, second is the artistic principle, the third is hydrophilic psychological impact. In this paper, the ecological, aesthetic, hydrophilic are closely contacted, with the guidance of the city wetland park improvement.
\end{abstract}

\section{Introduction}

Revetment is a transition region with land and water interact with each other, has the obvious edge effect. Revetment environment have important realistic and potential value on the increase of plant and animal species, beautify the environment, to develop tourism activities. Vegetation is an important factor of landscape revetment, based on repeatedly investigation with the South Lake urban wetland park in Tangshan city, The authors found some problems, such as individual revetment vegetation exists a single species, configuration mode is monotonous, ground cover plants are artificially stampede. This topic conducts the research to the vegetation revetment environment configuration, put forward three basic principles of vegetation disposition: first is the principle of ecology, second is the artistic principle, third is to focus on the influence of hydrophilic psychology.

\section{The principle of ecology}

On the basis of the characteristics of the environment to make the choice of plant species

1) Study on the characteristics of the vegetation growth. The morphology of vegetation community of urban wetland park should be community characteristics allocation according to the nature. Follow ecological laws, in order to form the virtuous cycle of wetland ecological system. From the lake shore, plant aquatic plants, aquatic plants, terrestrial plants, aquatic plants from the submerged plant transition to floating plant, from floating plant transition to aquatic plants; Wetland plant configuration, should pay attention to the collocation of hygrophyte herbs and Wetland Woody plants. In the natural slope revetment on this transition is obvious, while in some steep slope area due to vertical height difference is large, the lack of shallow water wet areas, lead to influence the natural growth of vegetation. In this case, need according to the needs of specific environment to choose the suitable vegetation species.

2) The regional study of vegetation selection. There are a lot of suitable vegetation species in revetment area. Native plant is preferred, because in the long-term adaptation process, native plants have formed a good combination with the local environment. For example, in South Lake Wetland Park in Tangshan, Use reed and lotus, these are the original local varieties. In addition, according to the characters of water area, choose different varieties of vegetation to create a different theme, in order to Creating a wetland landscape full of local characteristics. 


\section{Effect of vegetation on the environment}

1) Regulating effect of vegetation on climate. Revetment is the region with the highest rate of vegetation, the highest rate of vegetation have a moderating effect on the climate and environment, especially the influence on the regional microclimate is more obvious. Lotus Lake, reed marshes have significant influence on the wind direction and wind speed, trees along the shoreline play a lead role of guiding the direction of the wind. Vegetation has obvious function of regulating the temperature and humidity, Some scholars come to a conclusion through the method of experiment: Better vegetation cover area and non vegetated areas, in terms of decreasing temperature and increasing humidity in the air, there are significant differences, vegetation can decrease the average temperature of $2{ }^{\circ} \mathrm{C}$, the average relative humidity increases about $30 \%$ [1].

2) Effect of vegetation on Soil and water maintain. There is a certain slope at revetment area, affected by rainfall is easy to cause soil erosion problems. On the one hand, through the control of slope to achieve the purpose of reducing runoff velocity, on the other hand, the slope vegetation plays a very important role in the aspect of soil and water conservation. The vegetation of the ground part, especially the tall tree canopy, has the function of rainfall interception, greatly reduced the fall to the ground rainfall, therefore reduced surface runoff, reduced the erosion on surface soil; The surface of the litter layer also have the function of water conservation, weaken the raindrop splash, delaying the formation of Surface Runoff; Vegetation roots can affect soil moisture permeability, root will channel extrusion in the soil in the process of growth, in order to make the surface water may be down between the root and the surrounding soil contact surface into the soil[2], Playing a role in maintaining soil infiltration, guide the flow of water.

3) Effect of vegetation on water purification. Aquatic plant can absorb the Excessive nutrients in the water, can reduce the sediment suspension, and also has obvious effect on the purification of organic pollution of toxic[3]. Tangshan South Lake Park planting reeds, water hyacinth, Oriental water plantain rhizome, mint in particular the polluted area on the shore, these plants can promote water, has a significant role in the purification of water purification.

4) Effect of vegetation on animal survival activity. Waterfront environment is a area with small animal frequent activity, vegetation is the primary producer of Wetland, Provide habitat and food for the wetland animal. In the bulkhead near water area, there are a lot of software animal,

Dense reeds and terrestrial bushes become small animal habitat and refuge, revetment vegetation configuration more continuous animal activity space more complete, Natural attribute more thick is formed more stable balance of animals and plants.

\section{Vegetation configuration art principle}

Study on vegetation distribution. Some vegetation is suitable for appreciation of plant image, some vegetation is suitable for appreciation group image. Therefore, vegetation configuration layout should be according to the vegetation its ornamental characteristics, Vegetation arrangement can be divided into three methods: point layout、 linear layout、 planar layout.

1) Point layout. Point layout refers to the single plant on the shore of the landscape tree species, or a group planting on the shore of reeds, or a group of flower arrangement. The characteristics of this arrangement is distinct landscape features with the surrounding environment, easy to become the visual center, But if the point layout landscape is too much, will result in poor continuity of the landscape. Therefore, the point layout landscape configuration should not only pay attention to the set position, also need pay attention to quantity.

2) The linear layout. The linear layout is the most common environment in revetment vegetation configuration, such as the extending direction along the banks of the river reed marshes, coastal planting trees, showing a linear landscape obvious image. The characteristics of this configuration is the landscape of strong continuity and ecological stability, but if handled improperly, extremely easy to have the stiff, dull feeling. Linear vegetation landscape image is greatly affected by the form of the revetment, when the form of the revetment varied twists and turns, we only need to layout the vegetation along the shoreline can obtain abundant images, appear 
natural and vivid, When the concave convex revetment linear change is not abundant enough, then the vegetation elements layout along the coast line is too monotonous, therefore, we should pay attention to the shaping of linear vegetation landscape, to make the vegetation landscape from the original shoreline suddenly near or far, winding, full of change.

3) Planar layout. Configuration method of planar layout can be divided into two types, one is planting vegetation elements into a surface as a background, such as large area of grass planting, the other is planting vegetation element into a surface with a theme, such as South Lake Park in Tangshan's Lotus Pond. The theme of face shaped landscape is easy to attract people and become the center of landscape and tourist destination, especially suitable in the open waters of the shoreline turning area. In the vegetation, interspersed in the vegetation landscape can be arranged inside the trails, so that people can feel close to vegetation charm.

\section{Study on vegetation color}

1) Pay attention to the different colors of vegetation collocation. There are multiple factors in revetment , vegetation, soil, structures and other factors all have different color, these elements are combined, can form different color environment and landscape space art image. Green is the most common color of wetland vegetation, and the color of flowers in the vegetation configuration are widely used, such as saffronoleander, lotus and calamus; yellow flowered snapdragons, color Huang Changpu, vegetation in the green mountains, is particularly prominent and active, become the important elements to improve the environmental atmosphere .

2) Pay attention to color collocation of vegetation under different seasons. Rain in summer in the northern area is abundant, the lush growth of wetland vegetation in the fall and winter seasons; a large number of wetland plants withered, exposed soil layer. Therefore, the most attractive area in the fall and winter seasons not only gives a better feel for revetment this summer, but let people feel cold decay. Therefore, vegetation should be designed according to season. We should plant evergreen tree species and the appropriate color leaf and blossom plants, pay attention to the different vegetation leaf, flower, fruit collocation in the four seasons of color, the continuation of ornamental Wetland Park from time to time.

3) Pay attention to vegetation elements and other elements of the color match. Vegetation as the main elements of revetment, its color is the main color of revetment, soil, wood corridor, landscape stone revetment are also the important factors in revetment, these factors and vegetation factors of color matching, finally formed the overall color revetment feeling. The brown wooden road, flowers white stone walkways and brown pebble sting step against the green vegetation of the winding expansion, rich and vivid color combinations, easing into pieces of green to bring people's visual aesthetic exhaustion.

Vegetation configuration under the effect of hydrophilic psychology. Affected by

the hydrophilic psychology, people will have different behavior in

the revetment environment, vegetation allocation according to the characteristics of human behavior, can form symbiotic harmony adult and vegetation.

Vegetation configuration at the region where near the water. Plots of the lotus in full bloom and together tadpoles, will make the shore become people like reach area, people watch the water and play with the water at this area, and also people have a need to mobile along the coast line, especially some area with three sides full of water is easy to become the main area of people gathering. In the South Lake Park, due to the lack of people's psychological consider hydrophilic, some waters without ribbons of pedestrian road in coastal area, thus causing water vegetation was severely trampled consequences, lead to vegetation degradation phenomenon. Based on this, we can set the road in the area where the tourist activity is more frequent, road can use wooden platform slightly above the water surface or use the gravel belt.

Vegetation configuration at the region where far from the water. Far water area adjacent to the wetland park car road area, in this area, under the effect of hydrophilic psychology, people have far see demand for water. When vegetation is arranged in this area, We should consider that 
the visual route from the road to the water can not completely blocked by vegetation, therefore, try not to use the lush vegetation at the sight height. Tall trees and low ground cover plant combination is the most common configuration mode in this region, in order to break the monotony of the vegetation landscape, can properly set up shrubs, but should control the distance between the strain and strain, to avoid occlusion of the line of sight.

Vegetation configuration at the transition region. Attracted by water area landscape, people will have a behavior moving from the region where far away from the water to the region near the water. Therefore, in revetment landscape planning, we need to design the path bounding up the area which far from water and the area which close the water. Route handled properly, then people can follow the established route to reach the target region, processing undeserved, can spontaneously form multiple paths because of the lack of guidance, causing damage to the area of the original vegetation. Therefore, vegetation design and path design need to be considered together, the survey found a slight slope area and the area where has a closely contact with the shore landscape are easy to be selected as the path. When we transform the environment, we can reform the vegetation degradation area after the stampede, the regional planning into a path, because this region is examined by practice is the most suitable way of constructing; another method is plant Bush to hinder the flow role in easy stampede regions, can also play a role in the protection of vegetation near the water.

\section{Conclusions}

The city wetland park located in city, and therefore the public activities have a great impact on the park, People and vegetation has a obvious contradiction at Revetment area. This paper puts forward three vegetation configuration principles: the ecological, artistic, hydrophilicity. There principle has a great significance for improving the relationship between man and nature, and also can improve the image of the city.

\section{Reference:}

[1] Jing Li, Gennian Sun et al:Vegetation on summer line temperature / humidity regulating effects of experimental and ecological value, submitted to Land resources and environment, Vol.16 (2002),p.102-105 (in Chinese)

[2] Xiaonan Wang, Guangtao Meng:Mechanism of plant measures in key soil and water conservation, submitted to Soil and water conservation application technology, Vol.4 (2008),p.25-26 (in Chinese)

[3] Zhenbin Wu, Dongru Qiu: Effect of aquatic plants to purify eutrophicwater, submitted to Wuhan Botanical Research, Vol.19 (2001),p.299-303 (in Chinese) 